\title{
Controlling Ethylene's Action: Impact of 1-Methylcyclopropane on Agriculture: Introduction to the Colloquium
}

\author{
Penelope M. Perkins-Veazie \\ USDA-ARS, South Central Agricultural Research Laboratory, Highway 3 West, Lane, OK 74555 \\ Sylvia Blankenship \\ Department of Horticulture, North Carolina State University, Raleigh, NC 27685-7609
}

\begin{abstract}
1-Methylcyclopropane (1-MCP) is a gas that acts as an inhibitor of ethylene action. In the last 10 years, after patent approval (Sisler and Blankenship, 1996), the use of 1-MCP has become a global tool for commercial horticulture applications and has helped advance our knowledge of ripening and ethylene action in ripening and plant development.
\end{abstract}

1-MCP has a molecular weight of 4 and a formula of $\mathrm{C}_{4} \mathrm{H}_{6}$. 1-MCP has several roles related to ethylene; it has an affinity for ethylene receptors that is 10 times that of ethylene, it is active at much lower concentrations than ethylene, and it can influence ethylene biosynthesis through feedback inhibition
(Blankenship and Dole, 2003). Because of these actions and the ease of application of the compound, 1-MCP has proved to be a useful tool in separating ethylene-dependent from -independent actions such as softening, color formation, and aroma development.

Although 1-MCP was first developed for commercial use in cut flowers (SmartFresh, Spring House, PA), it has now been registered for use on many edible crops. Perhaps the most studied of these fruits are apples. Researchers in the United States and Canada have many cooperative studies on variety, temperature, and storage conditions to determine germplasm suitability, effective levels of 1-MCP, and specific storage changes to best maximize shelf life. In this colloquium, the application of 1-MCP, and the physiological and molecular changes occurring in response to this compound, are explored to provide a more complete picture of the state of 1-MCP in the fruit, vegetable, and nursery industries.

\section{Literature Cited}

Blankenship, S.M. and J.M. Dole. 2003. 1-Methylcyclopropene: a review. Postharvest Biol. Technol. 28:1-25.

Sisler, E.C. and S.M. Blankenship. 21 May 1996. Methods of Counteracting an ethylene response in plants. U.S. Patent No. 5,518,988 